\title{
Occurence and Antimicrobial Susceptibility Profile of Salmonella from Dairy Farms in and Around Meki Town, Oromia, Ethiopia
}

\author{
Fufa Abunna*1, Getachew Ngusie ${ }^{1}$, Takele Beyene Tufa ${ }^{1}$, Dinka Ayana ${ }^{1}$, Berhane Wakjira ${ }^{1}$, Hika Waktole ${ }^{1}$ and Reta \\ Duguma $^{1,2}$
}

${ }^{1}$ Addis Ababa University, College of Veterinary Medicine and Agriculture, Ethiopia

${ }^{2}$ University of Tennessee Knoxville, USA

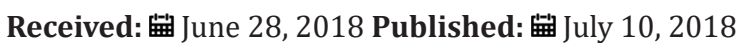

*Corresponding author: Fufa Abunna,Addis Ababa University, College of Veterinary Medicine and Agriculture,P.O. Box 34, Bishoftu, Oromia, Ethiopia

\begin{abstract}
A cross sectional study was conducted on dairy farms in Meki town and its surrounding from January 2016 to April 2016 with the aim of this research work was to isolate, identify and determine the in-vitro antimicrobial susceptible profile of Salmonella in an apparently healthy lactating cows and farm equipmentA total of 304 samples were aseptically collected from udder milk, feces of cows, pooled bucket swab, pooled tank swab, tank milk and pooled milker's hand swab.From the total of 304 samples examined, $11.2 \%$ were found to be Salmonella positive following the standard techniques and procedure out lined by International Organization for Standardization. There was no statistically significant association among sample types.

However, there was statistically significant difference in Salmonella isolation frequency of lactating animals from small and medium size farms. All isolates were resistant to at least one or more antimicrobials tested. Accordingly 97.06\%, 91.18\%, 73.53\%, 73.53\%, isolates showed resistance to ampicillin, amoxaciilin, streptomycin, naldixic acid respectively.Multiple antimicrobial resistances (resistance to three or more antimicrobials) were detected in $97.05 \%$. This study clearly indicates that Salmonella isolates shedded from feces can contaminate the milk, the farm equipments and personnel and result in bad hygienic standards of the farms. The current finding also revealed that there was higher percentage of multiple antimicrobial resistant isolates. Therefore, addressing the issue of antimicrobial resistance should be taken as one of the most urgent priorities otherwise it will be very difficult to cure clinical diseases if unwise use antimicrobials are practiced at the farm level.
\end{abstract}

Keywords: Dairy Farms; Meki; Multiple Antimicrobial Resistance; Salmonella

\section{Introduction}

Salmonella belongs to the family enterobacteriaceae [1]. According to the Centers for Disease Control and Prevention system, the genus Salmonella contains two species, each of which contains multiple serotypes. The two species are S. enterica, the type species and S. bongori, which were formerly subspecies V [2] Popoff and Le Minor [3] Reeves et al. Salmonellaenterica in turn is further divided in to six subspecies and the subspecies are differentiated biochemically and by genomic relatedness Heyndrickx et al. [4-6]. Members of the genus are gram negative, facultative anaerobic, oxidase-negative, rod-shaped bacteria and most of motile by peritrichous flagella except S. Pullorum and S. Gallinarum, which lack flagella and chemoorganotrophic, with ability to metabolize nutrients by the respiratory and fermentative pathways $[7,8]$. Salmonella grows between $80 \mathrm{C}$ and $450 \mathrm{C}$ (optimally at $37^{\circ} \mathrm{C}$ ) and at a pH of 4 to 9 . A temperature higher than $70^{\circ} \mathrm{C}$ rapidly kills them. Pasteurization at 71.1 0C for 15 seconds is sufficient to destroy salmonella in milk. These bacteria can resist dehydration for a very long time, both in feces and in foods for human and animal consumption. It has been indicated that they can survive for a long time in soil, water [9] and dried foodstuffs [10].

Salmonella infections in animals often carried asymptomatically $[5,8]$. The ways of management system, the epidemiological characterisc of different Salmonella species, the herd size, whether animals are housed or non housed are the factors that determine the clinical signs in large animals and Clinical disease usually appears when animals are stressed by factors such as transportation, crowding, food deprivation, weaning, parturition, a concurrent viral or parasitic disease, sudden change of feed, or overfeeding following a fast. The severity of Salmonella infection varies from asymptomatic carriage to fatal bacteremia. Mortality in young animals is high, however, it can be fatal in adult animals as well. The clinical signs vary with the infecting dose, health of the host, Salmonella serotypes and other factors [6]. Host adapted serotypes primarily cause abortions or severe gastroenteritis in 
their animal hosts. In food animals, a group of more frequently isolated serotypes, such as $S$. typhimurium, S. enteritidis, $S$. hadar and $S$. infantis, manifest themselves clinically through per-acute septicemia, acute enteritis or chronic enteritis. Dairy cows are one of and major reservoir for non typhoidal Salmonella in industrialized countries and large outbreaks of Salmonella infection have been associated with food-borne transmission including that from contaminated poultry and poultry products, meat, and milk and other dairy products [11].

National and global epidemiological registries continue to highlight the importance of Salmonella spp. as one of the leading cause of food borne bacterial zoonotic disease in humans [12-17]. The majorities of human Salmonellosis cases have been associated with the consumption of raw or inadequately heat treated dairy products. The presence of Salmonella species in raw milk generally comes from feces of infected animals. Diagnosis of infected animals is difficult due to asymptomatic or subclinical infection and the fact that affected cows can shed as many organisms in their manure, providing an easy route of contamination during milking and milk processing. Salmonella presence in milk and some dairy products emerged as major public health concern to human consumers, causing great public health problem, as Salmonellosis is an important zoonotic disease and being one of the most commonly reported causes of food borne disease over the past century [18]. Salmonellosis is one of the most wide spread food-borne zoonoses in Ethiopia [16].

Antimicrobial agents represent one of the main tools both in human and veterinary medicine to control and treat variety bacterial infectious diseases. However, during the past decades, the use and misuse of antimicrobials in both human and veterinary medicine has resulted in the emergence resistant Salmonella strains that no longer respond to antimicrobial therapy probably due to continuous antibiotic pressure [19-21]. Antibiotic resistance in Salmonella is an emerging problem Rodriguez et al. The routine practice of giving antimicrobials to domestic livetock for prohylaxis and growth promotion is an important factor in the emergence antibiotic resistance bacteria in the food chain $[22,23]$. The major transmission path way for resistance bacteria and resistance genes from food animals to humans is the food chain [24]. Not only antimicrobial- resistant Salmonella pathogens in animals pose a risk in terms of animal health, but also affect public health due to raise health care costs as result of treat failure [25]. Salmonella species are resistant to multiple antibacterial like sulfonamides, ampicillin, streptomycin, chloramphenicol and tetracyclines [26].

In spite of different studies conducted in Ethiopia indicating considerable prevalence of Salmonella both in veterinary and public set ups reported by [27-29] Zewdu and Cornelius, the isolation of Salmonella from apparently healthy lactating cows, farm equipments and humans attending these cows was not investigated so far in Meki or elsewhere in Ethiopia. Therefore, the objectives this study were to isolate, identify Salmonella spp. from apparently healthy lactating cows, farm equipments and humans in and around Meki town dairy farms and to investigate the susceptibility of Salmonella isolates to antimicrobial agents used in veterinary and human medicine for the treatment of Salmonellosis and other bacterial diseases.

\section{Materials and Methods \\ Study Area}

The study was conducted in Meki town, located in Oromia Regional State about $134 \mathrm{~km}$ South East of Addis Ababa, just on the main road to Hawassa town. It is the administrative town of Dugda district which is found at $8001^{\prime}$ to $8010^{\prime}$ North latitude and 38031' to $38057^{\prime} \mathrm{E}$ longitude. The area receives an average annual rain fall of $800 \mathrm{~mm}$ with the main rainy season extending from June to August (of which $84 \%$ of rain is expected) and a short rainy season from March to May. The mean annual minimum and maximum temperatures are $11.4^{\circ} \mathrm{C}$ and $24.8^{\circ} \mathrm{C}$, respectively with an overall average of $17.9^{\circ} \mathrm{C}[30]$.

\section{Study Population}

Apparently healthy lactating dairy cows were selected from small and medium sized dairy farms in and around Meki town. Small size farm is dairy farm with less than 25 heads and where as medium size farm with 26 to 50 heads [31]. Nineteen private dairy farms enrolled in the study, 16 were small and the rest 3 were medium size. Lactating cows under antibiotic treatment were excluded from the study. The number of lactating cows kept in the study dairy farms varies from 5 to 50 cows per farm. Cows were milked twice per day in all dairy farms.

\section{Study Design}

A cross sectional study was employed from January 2016 to April 2016 at private dairy farms in and around Meki town. Individual animals in farm were selected randomly to isolate, identify Salmonella by conventional cultural and biochemical methods and to determine the in-vitro antimicrobials susceptibility profile Salmonella isolates to panel of antimicrobial agents. Each farm was visited once from January 2016 to April 2016. Days for sampling were randomly assigned to each dairy farm. Prior to sample collection preliminary visit was made on the distribution to the dairy farms so as to know the name and list of farms in Meki. During our visit, dairy farm milker's were informed that they were going to be sampled and requested for cooperation. On each day of sampling at farm, six lactating cows were randomly selected and identified by their ID number to animals with ID number or by code to animals that have no ID at farm, before the milking operation. Udder milk and feces were collected from each selected lactating cows. Besides, pooled bucket swab, pooled tank swab, tank milk and pooled milker's hand swab from apparently healthy person milker's were collected.

\section{Sample Size}

Sample size was defined using the formula [32] with expected prevalence taken from previous study in Addis Ababa $10.7 \%$ [27] at $95 \%$ confidence interval and significance level of 5\%. Based on the above formula the calculated sample size was 147. But the total number of samples collected was 304 which is twice the previous studied sample size. 


$$
N=\frac{(Z)^{2} p(1-p)}{d^{2}}
$$

Where: $\mathrm{Z}$ = statistics for a level of confidence, $\mathrm{P}=$ expected prevalence or proportion, $\mathrm{d}=$ absolute precision.

\section{Sample Collection}

All samples were collected aseptically from lactating cows during milking operations. On each day of Sampling, 16 samples per farm including 6 udder milk, 6 fecal sample, 1pooled bucket swab, 1 pooled tank swab, 1 tank milk and 1 pooled milker's hand swab samples were collected from the dairy farm. A total of 114 udder milk, 114 fecal, 19 pooled bucket swab, 19 pooled tank swabs, 19 tank milk and 19 pooled milker's hand swab were collected. About $25 \mathrm{ml}$ milk samples were collected in sterile universal bottles at midstream from each cows. Pooled milker's hand swab, pooled bucket swab and pooled tank swab were collected before the beginning of milking process and approximately 25gram of fecal matter were collected directly from the rectum using disposable gloves into sterile screw-capped glass bottle at the end of milking operation.

All samples were labeled legibly with permanent marker identifying type of sample, date of sampling and name of the farm. Swab samples with in test tubes were shaken for 30 seconds for uniform distribution of microorganisms before transportation. The samples were then transported on ice box to Microbiology Laboratory of Addis Ababa University College of Veterinary Medicine and Agriculture at Bishoftu for processing and analysis upon arrival or kept at 40Cover night.

\section{Biochemical confirmation of Salmonella isolates}

Typical or suspected Salmonella colonies were subjected to the series biochemical tests (ISO6579 2002; Quinn et al. Isolates of presumptive of Salmonella for all biochemical tests were cultured on Nutrient Agar (HIMEDIA) for antimicrobial susceptibility testing.

\section{Antimicrobial Susceptibility Testing}

The Kibry-Bauer disk diffusion method was employed for the determination of antimicrobial susceptibility of the Salmonella isolates which conforms to the recommended standards of the Clinical and Laboratory Standards Institute [33]. The diameter of zones of inhibition was measured to the nearest millimeter using digital caliber and classified as sensitive, intermediate and resistant according to published interpretive chart [33].

\section{Data Analysis}

The data obtained was entered to the excel spread sheet (Microsoft office ${ }^{\circledR}$ excel 2007) and analyzed using SPSS version 20 software. The result proportion analyzed using descriptive analysis. Proportion was estimated as the number of samples detected positive to Salmonella isolation from the total analyzed. Chi-squire test was used to assess significant differences between sample types and Salmonella status. The results with less than P-value of 5\% were considered statistically significant

\section{Results}

\section{Frequency of Salmonella Isolation}

From the total of 304 samples from udder milk, feces, pooled bucket swab, pooled tank swab, tank milk and pooled milker's hand swab examined, $11.2 \%$ (34/304) were found to be Salmonella positive. A total of 114 dairy cows examined in 19 dairy farms, $24.56 \%$ (28/114) were positive for Salmonella either from milk or fecal samples or both (Table 1). Of these cows, 71.43 (20/28) were positive from fecal sample and $28.57 \%(8 / 28)$ from milk samples. From biochemically confirmed Salmonella positive isolates, one lactating cow was found positive from both milk and fecal samples. The larger percentage of Salmonella were isolated from fecal samples (71.43 \%) compared to $(28.57 \%)$ from milk samples. The rate of milk and fecal shedding of Salmonella by lactating cows were $7 \%$ and $17.5 \%$, respectively. Salmonella isolates were obtained in $7.02 \%$ udder milk, $17.54 \%$ feces, $15.79 \%$ pooled bucket swab, $10.53 \%$ pooled tank swab and $5.26 \%$ pooled milker's hand swab of the total positive isolates. No Salmonella was isolated from tank milk (Table 1). The difference in prevalence in different sample types detected was not statistically significant $(\chi 2=10.11 ; \mathrm{df}=5$ $\mathrm{p}$-value $=0.072$ )

Table 1: Occurrence Salmonella isolate in dairy farms by sample types.

\begin{tabular}{|c|c|c|c|}
\hline \multirow{2}{*}{ Sample type } & $\begin{array}{c}\text { Numbers } \\
\text { samples }\end{array}$ & & \\
\cline { 2 - 4 } Examined & Positive (\%) & $\chi \mathbf{2}$ (p-value) \\
\hline Udder milk & 114 & $8(7.02)$ & \\
\hline Feces & 114 & $20(17.54)$ & \\
\hline $\begin{array}{c}\text { Pooled bucket } \\
\text { swab }\end{array}$ & 19 & $3(15.79)$ & $10.11(0.072)$ \\
\hline $\begin{array}{c}\text { Pooled tank } \\
\text { swab }\end{array}$ & 19 & $2(10.53)$ & \\
\hline Tank milk & 19 & $0(0)$ & \\
\hline $\begin{array}{c}\text { Pooled milker's } \\
\text { hand swab }\end{array}$ & 19 & $1(5.26)$ & \\
\hline Total & 304 & $34(11.18)$ & \\
\hline
\end{tabular}

Table 2: Occurence of Salmonella in small and medium sized dairy farms.

\begin{tabular}{|c|c|c|c|}
\hline Sample type & \multicolumn{2}{|c|}{ Farm size } & $\chi 2$ p-value \\
\hline & Small & Medium & \\
\hline Udder milk & & & \\
\hline Positive & $3(3.12)$ & $5(27.78)$ & 14.120 .00 \\
\hline Negative & $93(96.88)$ & $13(72.22)$ & \\
\hline Total & $96(100)$ & $18(100)$ & \\
\hline Feces & & & \\
\hline Positive & $12(12.5)$ & $8(44.44)$ & $10.690 .00)$ \\
\hline Negative & $84(87.5)$ & $10(55.56)$ & \\
\hline Total & $96(100)$ & $18(100)$ & \\
\hline $\begin{array}{c}\text { Pooled bucket } \\
\text { swab }\end{array}$ & & & \\
\hline Positive & $0(0)$ & $3(100)$ & $19.00(0.00)$ \\
\hline
\end{tabular}




\begin{tabular}{|c|c|c|c|}
\hline Negative & $16(100)$ & $0(0)$ & \\
\hline Total & $16(100)$ & $3(100)$ & \\
\hline \multicolumn{4}{|l|}{$\begin{array}{c}\text { Pooled tank } \\
\text { swab }\end{array}$} \\
\hline Positive & $1(6.25)$ & 1(33.33) & 1.970 .16 \\
\hline Negative & $15(93.75)$ & $2(66.67)$ & \\
\hline Total & $16(100)$ & $3(100)$ & \\
\hline \multicolumn{4}{|l|}{ Tank milk } \\
\hline \multicolumn{4}{|l|}{ Positive } \\
\hline \multicolumn{4}{|l|}{ Negative } \\
\hline \multicolumn{4}{|l|}{ Total } \\
\hline \multicolumn{4}{|l|}{$\begin{array}{c}\text { Pooled } \\
\text { milker's hand } \\
\text { swab }\end{array}$} \\
\hline Positive & $0(0)$ & $1(33.33)$ & \multirow{3}{*}{5.630 .02} \\
\hline Negative & $16(100)$ & $2(66.67)$ & \\
\hline Total & $16(100)$ & $3(100)$ & \\
\hline
\end{tabular}

From the total of 19 private dairy farms enrolled in this study, Salmonella were isolated from 17 (89.47\%) farms. Of these farms, 16 were small and the rest 3 were medium size. From these 16 (47.1\%) and 18 (52.9\%) Salmonella isolates were obtained from small size and medium size farms respectively. The isolation rate varies $3.1 \%$ to $27.8 \%$ between small and medium size farms. About $27.28 \%$ $(9 / 16)$ animals were Salmonella positive from medium size farm, where as $3.12 \%$ animals from small size. There was statistically significant difference in Salmonella isolation frequency between small and medium sized dairy farms $(\chi 2=39.739 ; \mathrm{df}=1$; $\mathrm{p}$-value= $0.000)$.The detection rate of Salmonella in udder milk, feces, pooled bucket swab, pooled milker's hand swab those lactating cows found in small and medium size farms was statistically significant $(p=0.00)$ (Table 1). The detection rate of Salmonella in udder milk of medium size lactating cows was greater than those lactating cows in small size farms (Table 2).

\section{Antimicrobial Resistance Pattern of Salmonella}

All Salmonella isolates were resistant to one or more antimicrobial agents tested. From 34 resistant isolates, 97.06\%, $91.18 \%, 73.53 \%, 73.53 \%, 67.65 \%$ and $50 \%$ isolates showed resistance to ampicillin, amoxaciilin, streptomycin, naldixic acid, kenamycin and chloramphenicol respectively. However, none of isolates were showed resistance to ciprofloxacin, meaning all isolates were sensitive to ciprofloxacin (Table 3). About $60 \%(12 / 20)$ of fecal isolates from dairy farms showed marked resistance to amoxicillin, ampicillin, kenamycin, naldixic acid and streptomycin, however, they were sensitive to ciprofloxacin. Three isolates of bucket swab from different farm showed different resistance pattern: AMC, AMP, K, NA S, AMP, NA, S and AMC, AMP, $\mathrm{S}$ to five, three, three antimicrobials respectively. The isolate from tank swab showed resistance to six antimicrobials i.e. amoxicillin, ampicillin, chloramphenicol, kenamycin, naldixic and streptomycin.
On the other hand, the second tank swab from another farm showed resistance to five antimicrobials namely amoxicillin, ampicillin, kenamycin, naldixic acid and streptomycin. The isolate from milker's hand swab showed resistance to amoxicillin, ampicillin, kenamycin and streptomycin.

Table 3: Antimicrobial susceptibility test results of Salmonella isolates from dairy farms.

\begin{tabular}{|c|c|c|c|c|}
\hline \multirow{2}{*}{$\begin{array}{c}\text { Antimicrobial } \\
\text { agent }\end{array}$} & \multirow{2}{*}{$\begin{array}{c}\text { Number } \\
\text { of total } \\
\text { isolates } \\
\text { tested }\end{array}$} & \multicolumn{3}{|c|}{$\begin{array}{c}\text { Antimicrobial susceptibity patterns } \\
\text { (\%) }\end{array}$} \\
\cline { 3 - 5 } & 34 & Sensitive & Intermediate & Resistant \\
\hline AMC & 34 & $0(0)$ & $3(8.82)$ & $31(91.18)$ \\
\hline AMP & 34 & $30(88.2)$ & $2(5.88)$ & $2(5.88)$ \\
\hline FOX & 34 & $6(17.65)$ & $11(32.35)$ & $17(50)$ \\
\hline C & 34 & $34(100)$ & $0(0)$ & $0(0)$ \\
\hline CIP & 34 & $27(79.41)$ & $1(2.94)$ & $6(17.65)$ \\
\hline CN & 34 & $3(8.82)$ & $8(23.53)$ & $23(67.65)$ \\
\hline K & 34 & $2(5.88)$ & $7(20.58)$ & $25(73.53)$ \\
\hline NA & 34 & $5(14.71)$ & $4(11.76)$ & $25(73.53)$ \\
\hline S & 34 & $27(79.41)$ & $5(14.71)$ & $2(5.88)$ \\
\hline SXT & & & \\
\hline
\end{tabular}

Key for Abbrevations: $\mathrm{AMC}=$ Amoxacillin, $\mathrm{AMP}=$ Ampicillin, $\mathrm{FOX}=$ Cefoxitin, $\mathrm{C}=$ Chloramphenicol, $\mathrm{CIP}=$ Ciprofloxacin, $\mathrm{CN}=$ Gentamycin, $\mathrm{K}=$ kenamycin, $\mathrm{NA}=$ Naldixic acid, S=Streptomycin, SXT= Sulfamethoxazole trimethoprim

Table 4: Multiple antimicrobial resistance pattern of Salmonella isolates from Mekidairy farms.

\begin{tabular}{|c|c|c|}
\hline $\begin{array}{c}\text { No of } \\
\text { antimicrobials }\end{array}$ & $\begin{array}{c}\text { Antimicrobial resistance } \\
\text { pattern(number of isolates) }\end{array}$ & No of isolates (\%) \\
\hline \multirow{6}{*}{ Three } & $\mathrm{AMC}, \mathrm{C}, \mathrm{NA}(1)$ & \multirow{5}{*}{$7(21.21)$} \\
\hline & AMC, AMP, K(2) & \\
\hline & AMC, AMP, S(1) & \\
\hline & AMC, AMP, NA(1) & \\
\hline & AMP, NA, S(1) & \\
\hline & AMP, NA, S(1) & \\
\hline \multirow{4}{*}{ Four } & AMC, AMP, NA, S(2) & \multirow{4}{*}{$5(15.15)$} \\
\hline & AMC, AMP, K, S(1) & \\
\hline & AMC, AMP, K, NA(1) & \\
\hline & AMC, AMP, C, S(1) & \\
\hline \multirow{5}{*}{ Five } & AMC, AMP, K, NA, S(5) & \multirow{5}{*}{$9(27.28)$} \\
\hline & AMC, AMP, C, NA, S(1) & \\
\hline & AMC, AMP, C, K, S(1) & \\
\hline & AMC,AMP, CN, K, S(1 & \\
\hline & AMC, AMP, FOX, NA, S(1) & \\
\hline \multirow{2}{*}{ Six } & AMC, AMP, C, K, NA, S(7) & \multirow{2}{*}{$8(24.24)$} \\
\hline & AMC, AMP, C, CN, NA, S(1) & \\
\hline \multirow{3}{*}{ Seven } & AMC, AMP, C, CN, K, NA, S(1) & \multirow{3}{*}{$3(9.09)$} \\
\hline & $\begin{array}{c}\text { AMC, AMP, FOX, C, CN, K, } \\
\text { NA(1) }\end{array}$ & \\
\hline & AMC, AMP C CN K NA SXT(1) & \\
\hline Eight & $\begin{array}{c}\text { AMC, AMP, C, CN, K, NA, S, } \\
\text { SXT(1) }\end{array}$ & $1(3.03)$ \\
\hline
\end{tabular}


Multiple antimicrobial resistances (resistance to three or more antimicrobials) were detected in $97.05 \%$ (33/34) of the resistance isolates. Out of these multiple antimicrobial resistant isolates, $57.57 \%(19 / 33)$ and $24.24 \%$ (8/33) isolates were from feces and udder milk respectively. 21 different antimicrobial resistance patterns were observed from the total isolates (Table 4). One octa resistance Salmonella isolates with resistance pattern: AMC AMP C CN K NA S SXT and three isolates with different hepta resistant pattern: AMC, AMP C CN K NA S, AMC AMP FOX C CN K NA and AMC AMP C CN K NA SXT were seen. Eight isolates were with hexa resistant pattern from them one isolate was with different resistance pattern: AMC AMP C CN NA S and the other seven Salmonella isolates showed the same resistance pattern: AMC AMP C K NA S where as nine isolates were penta resistant in which four of them with different resistance pattern: AMC AMP C NA S, AMC AMP C K S, AMC AMP CN K S, AMC AMP FOX NA S and the remaining five isolates showed similar resistance pattern: AMC AMP K NA S(5). Five tetra resistant Salmonella isolates were also seen in which three isolates showing different resistance pattern: AMC, AMP, K, S(1), AMC, AMP, K, NA(1), AMC, AMP, C, S(1)and two isolates were with the same resistance pattern: AMC AMP NA S(3). Seven Salmonella isolates were resistant to three antimicrobial of two with similar resistance pattern: AMC AMP K(2) and the other five isolates with different resistance pattern: AMC, C, NA(1), AMC, AMP, S(1), AMC, AMP, NA(1), AMP, NA, S(1) and AMP, NA, S(1). No Salmonella isolates were found resistant to two antimicrobial agents.

\section{Discussion}

The current cross sectional study was designed to isolate, identify and to determine the antimicrobial susceptibility of Salmonella among lactating dairy cows in and around Meki town. Salmonella species, as a marker of food products safety, is widely distributed food borne pathogen by [34]. The presence and growth of Salmonella in milk, feces, farm equipments and humans have been investigated because of their health significance. From the total of 304 samples from farms examined for Salmonella, 11.2\% (34/304) were positive; of which 7.02\% (8/114), 17.54\% (20/114), 15.79\% (3/19), 10.53\% (2/19) , 5.26\% (1/19) and 0\% were positive from udder milk, feces, pooled bucket swab, pooled tank swab, pooled milker's hand swab and tank milk respectively. It was not possible to compare the overall prevalence obtained from these six sample types because studies made on Salmonella isolated from udder milk, feces, pooled bucket swab, pooled tank swab, tank milk and pooled milker's hand swab was not clearly studied and published in Ethiopia or elsewhere in the world.

From the sample types higher number of Salmonella was isolated from fecal sample and this prevalence of fecal shedding indicate the magnitude of environmental contamination possible. The isolation frequency of present finding in fecal sample was greater $(17.54 \%)$ than the report from [31,27] with prevalence of $9.3 \%(8 / 86)$ and $7.7 \%(15 / 195)$ respectively. And thus fecal collected from these lactating cows could contaminate the milk, farm equipments and personnel and this most likely pose risk to the farm personnel and the community at large for Salmonella infection. This higher prevalence from fecal sample in this study is also an alarm to the dairy company and could predispose the community to food poisoning outbreaks in large scale. This difference in prevalence with current finding might be due to difference in incubation temperature used for Rappaport Vasiliad is Soy Broth.

This current finding of fecal prevalence 17.54\% (20/114) among lactating cows was in line with the fecal Salmonella isolation rate of $17 \%(5 / 30)$ reported by $[35,36]$ a study conducted to investigated the prevalence of cattle shedding Salmonella in their feces at the NDSU dairy and to test antimicrobial susceptibility of Salmonella isolates. However, extremely higher prevalence fecal Salmonella 70\% (35/50) was reported by Bischoff et al. compared to the present who studied the characterization of antimicrobial resistant Salmonella Kinshasa from dairy calves in Texas. This higher difference in Salmonella shedding rate could be due to the specific host requirement in which 22 isolates were Salmonella Kinshasa out of 35 total isolates.

Out of 114 lactating animals examined in the present study from dairy farms, $24.56 \%$ (28/114) were positive for Salmonella either from milk or fecal samples or both. In this finding, however, the number of Salmonella isolates was higher than that of $[37,38]$ who reported $20 \%$ and $3.63 \%$ Salmonella from raw milk in Jimma and Iran respectively. This higher result in the present day could be due to the involvement of fecal samples and the simultaneous culture of sample types on S-S agar in addition to culturing on BGA and XLD selective plating media. From the total of 28 positive udder milk and feces samples, $71.43 \%(20 / 28)$ were positive from fecal sample and $28.57 \%$ (8/28) from udder milk samples. This current finding was very interestingly in agreement with isolation frequency of [27] who reported $71.4 \%$ from faecal and $28.6 \%$ milk sample in the study of Salmonella isolated from lactating cows and in contact humans in dairy farms of Addis Ababa. This study indicated that the isolation of Salmonella was greater (27.78\%) in animals of medium sizeddairy farms compared to animals in small sized dairy farms which were $3.12 \%$. The potential for herd carrier status increases with herd size, and shedding status may be influenced by stresses that result from variables [1].

Regarding the tank milk, no Salmonella was found from 19 samples tested and this result is in agreement with Myada \& Maha [39] who were not detect Salmonella in 50 of the examined bulk tank milk samples by conventional culture methods. However, the culture negative samples (50) from [39] were test by PCR and $24 \%$ $(12 / 50)$ were PCR positive. This extreme difference with current result is due to PCR assay superior to the conventional culture methods and biochemical tests for the detection of Salmonella isolates because PCR is sensitive and specific [40]. The number of Salmonella isolated of current study from bucket swab was higher $3 / 19$ (15.79\%) than a report from [41] who reported 1/7 (14.3\%). This difference may due to more Salmonella contaminated water either from environment or other is used for the washing and cleaning bucket swab in current study farms.

All the Salmonella isolates showed at least antimicrobial resistance to a single antimicrobial subjected to a panel of ten antimicrobial agents available on the market. From 34 isolates, 
$34(100 \%)$ of them were resistance to one or more antimicrobials tested. This finding can indicate that misuse of antimicrobial agents in animal production and treatment failure as a result of drug resistance, food poisoning outbreaks would be difficult to treat. This finding was in harmony with [41] who reported $100 \%$ resistance of all Salmonella strains isolated from raw milk in Sebeta, Ethiopia. Out of the 33 resistant isolates 97.06\%, 91.18\%, $73.53 \%, 73.53 \%, 67.65 \%$ and $50 \%$ isolates showed resistance to ampicillin, amoxaciilin, streptomycin, naldixic acid, kenamycin and chloramphenicol respectively. The result was in comparable to findings of [27] who reported $100 \%$ and $66.7 \%$ resistance to ampicillin and streptomycin respectively. The reason for this discrepancy may be as a result of the escalating rate of improper use of antimicrobials in the livestock production.

All isolates of Salmonella from lactating cows, humans and farm equipments showed $100 \%$ efficacy to the antimicrobial agent ciprofloxacin. This finding was in harmony with reports in Ethiopia Salmonella isolated from lactating cows and in-contact humans in dairy farms which showed $100 \%$ sensitivity and in line with report in Sudan in which ciprofloxacin was $100 \%$ effective to all human and cattle Salmonella isolates reported by [42]. The effectiveness of ciprofloxacin might be because they are not widely used in dairy farm production or other animal productions in Ethiopia even though no data was obtained. Multiple drug resistance (resistance to three or more antimicrobials) were detected in $97.05 \%(33 / 34)$ of the resistance isolates and this was higher than other studies conducted in Ethiopia by $[36,29,43]$ and elsewhere in the world by [44-47]. This greater resistance observed at this study might be due to the inappropriate and improper utilization of antimicrobials in the livestock production which favors selection pressure. A total of 21 different antimicrobial resistance patterns were observed. One isolate was found octa resistance pattern and three isolates were resistant to seven antimicrobials with different resistant pattern.

Eight isolates were resistant to six antimicrobials in which one isolate was with different resistance patter and the other seven Salmonella isolates showed the same resistance pattern. Nine Salmonella isolates were resistant to five antimicrobials of four of them with different resistant pattern and the remaining five isolates showed similar resistance pattern. Five isolates were also found resistant to four antimicrobials: three isolates showing different resistance pattern and two isolates were with the same resistance pattern: Seven Salmonella isolates were resistant to three antimicrobial of two with similar resistance pattern and the other five isolates with different resistance pattern. [41] Reported Salmonella isolates developed resistance to antimicrobials such ampicillin, streptomycin and sulfamethoxazole used in veterinary medicine and public health.

\section{Conclusion}

Salmonella spp. is among the most common causes of human bacterial gastroenteritis worldwide and food animals are important reservoirs of the bacteria. The transmission of Salmonella to humans occur through different ways such consumption contaminated food, food products and direct contact with animals. Management system, the epidemiological characteristics of different Salmonella species, the herd size and housing system are among the factors that determine the occurrence of Salmonella in animals. The present study reveal isolation, identification and antimicrobial resistance of Salmonella indairy cows, dairy cow's derivative food, farm equipments and in contact humans in dairy farms which are a potential source of antimicrobial resistance Salmonella. In general, from the current cross sectional study it can be concluded that $11.2 \%$ Salmonella was isolated from the total of 304 samples in and around Meki dairy farms. Of this (17.54\%) and (15.7\%) of Salmonella was isolated from fecal sample and pooled bucket respectively. This study clearly indicates that Salmonella isolates shedded from feces can contaminate the milk, the farm equipments and personnel and result in bad hygienic standards of the farms. The current finding also revealed that there was higher percentage of multiple antimicrobial resistant isolates (97.05\%).

\section{Acknowledgement}

The authors would like to thank Addis Ababa University Office of the Vice President for Research and Technology Transfer for financial support. We also acknowledge the priceless support given by the dairy farm owners.

\section{References}

1. Radostits OM, Gay CC, Hinchcliff KW (2006) Veterinary Medicine: A text book of the diseases of Cattle, Horses, Sheep, Pigs, and Goats, $\left(10^{\text {th }}\right.$ Edition). Saunders Elsevier publisher pp. 896-919.

2. Popoff MY, Le Minor L (1997) Antigenic formulas of the Salmonella serovars $7^{\text {th }}$ revision. WHO Collaborating Centre for Reference and Research on Salmonella, Institut Pasteur. Research in Microbiology 152: 907-909.

3. Reeves MW, Evins GM, Heiba AA, Plikaytis BD, Farmer JJ (1989) Clonal nature of Salmonella Typhi and its genetic relatedness to other salmonellae as shown by multilocus enzyme electrophoresis and proposal of Salmonella Bongori comb. Journal Clinical Microbiology 27(2): 313-320.

4. Heyndrickx M, Pasmans F, Ducatelle R, Decostere A, Haesebrouck F (2005) Recent changes in Salmonella nomenclature: The need for clarification. The Veterinary Journal 170(3): 275-277.

5. OIE (Office of International Epizootis) (2005) Salmonellosis: Paratyphoid, non-typhoidal salmonellosis. Institute for International Cooperation in Animal Biologics. An OIE Collaborating Center for Food Security and Public Health, Iowa State University, College of Veterinary Medicine.

6. Guibourdenche M, Roggentin P, Mikoleit M, Fields PI, Bockemuhl J, et al. (2010) Supplement 2008-2010 (no. 48) To the White-Kauffmann-Le Minor scheme. Research in Microbiology 161(1): 26-29.

7. D’AoustJY, DoyleMP, Beuchat LR, Montville TJ (1997) Salmonella species. Food Microbiology Fundamentals and Frontiers. ( $3^{\text {rd }}$ Edition) ASM Press, Washington DC, USA, pp. 129-158.

8. Forshel, Wierup M (2006) Salmonella contamination: a significant challenge to the global marketing of animal food products. Revue Scientifiqueet Technique 25: 541-554.

9. (1988) WHO (World Health Organization) Salmonellosis control: the role of animal and product hygiene. Report of a WHO Expert Committee, World Health Organization Technical Report Series 774, Geneva, USA, p. 7- 82 .

10. SleighJD, Duguid JP (1989) Salmonella In: Colle JG, Duguid JP, Fraser G, Marmio BP (Eds.). Mackie and McCartney Practical Medical Microbiology. $13^{\text {th }}$ (Edn.). Longman, UK 2: 456-481. 
11. Threlfall EJ (2000) Epidemic Salmonella Typhimurium DT 104-a truly international multi resistant clone. Journal of Antimicrobial Chemotherapy 46(1): 7-10.

12. D'Aoust JY (2000) Salmonella In: Lund BM, Baird-Parker TC, Gould GW (Eds.). The microbiological safety and quality of food. Aspen publishers pp. 1233-1279.

13. David GW, Shaohua Z, Robert Sudler MS, Sherry A, Sharon Friedman BA, et al. (2001) The isolation of antibiotic-resistant Salmonella from retai ground meats. The New England Journal of Medicine 345: 1147- 1154.

14. GiovannacciI, Queguiner S, Ragimbeau C, Salvat G, Vendeuvre J, et al. (2001) Tracing of Salmonella spp. in two pork slaughter and cutting plants using serotyping and macrorestriction genotyping. Journal of Applied Microbiology 90(1): 131-147.

15. Hjartardóttir S, Gunnarsson E, Sigvaldadóttir J (2002) Salmonella in sheep in Iceland. ACTA Veterinaria Scandinavica 43(1): 43-48.

16. Molla B, Alemayehu D, Salah W (2003) Sources and distribution of Salmonella serotypes isolated from food animals, slaughterhouse personnel and retail meat products in Ethiopia: 1997- 2002. Ethiopian Journal of Health Development 17(1): 63-70.

17. Mølbak K, John EO, Henrik CW (2006) Salmonella infections. In: Foodborne infections and intoxications, Elsevier Inc pp. 57-114.

18. Ryser ET (1998) Public Health Concerns. In: Applied Dairy MicrobiologyMarth EH, JL Steel (Eds.). Marcel Dekker, Inc, New York, NY, USA.

19. Cabrera R, Ruiz J, Marco F, Oliveira I, Arroyo M, et al. (2004) Mechanism of resistance to several antimicrobial agents in Salmonella clinical isolates causing traveler's diarrhea. Antimicrobial agents and chemotherapy 48(10): 3934-3939.

20. ChiuC, Su L, Chu C (2004) Salmonella entericasero type Choleraesuis: epidemiology, pathogenesis, clinical disease and treatment. Clinical Microbiology Reviews 17(2): 311-322.

21. Schroeter A, Hoog B, Helmuth R (2004) Resistance of Salmonella isolates in Germany. Journal of Veterinary Medicine Series 51(8-9): 389-392.

22. Tollefson L, Altekruse SF, Potter ME (1997) Therapeutic antibiotics in animal feeds and antibiotic resistance. Revue Scientifique Et Technique De' Office International Des Epizooties 16(2): 241-249.

23. Lashley FR, Durham JD (2007) Emerging Infectious Diseases: Trends and issues. ( $2^{\text {nd }}$ Edition). Springer Publishing Campany, LLC 11 West $42^{\text {nd }}$ Street. New York, USA p. 447.

24. (2003) Food and Agriculture Organization of United Nations (FAO), World Health Organization (WHO) and World Organization for Animal Health (OIE). 2003. Joint FAO/OIE/WHO expert work shop on nonhuman antimicrobial usage and antimicrobial resistance: Scientific assessment. Geneva, USA.

25. Gorbach SL (2001) Antimicrobial use in animal feed-time to stop. New England Journal of Medicine 345(16): 1202-1203.

26. Ashraf MA, Hiroyoki N, Tadashi S (2005) Molecular characterization of integrons in non-typhoidal Salmonella serovars isolated in Japan. Journal ofantimicrobial chemotherapy 55(3): 371-374.

27. Addis Z, Kebede N, Sisay Z, Alemayehu H, Yirsaw A, et al. (2011) Prevalence and antimicrobial resistance of Salmonella isolated from lactating cows and in contact humans in dairy farms of Addis Ababa: a cross sectional study. BMC Infectious Diseases 11: 222.

28. Ejeta G, Molla B, Alemayehu D, Muckle A (2004) Salmonella serovars isolated from minced meat beef, mutton and pork in Addis Ababa, Ethiopia. Revue de Médecine Vètérinaire 155(11): 547-551.

29. Zewdu E, Cornelius P (2009) Antimicrobial resistance pattern of Salmonella serotypes isolated from food items and personnel in Addis Ababa, Ethiopia. Tropical Animal Health and Production 41(2): 241-249.
30. NMSA (2005) National Metrological Service Agency. Addis Ababa, Ethiopia.

31. Hailu D, Gelaw A, Molla W, Garedew L, Linda C, et al. (2015) Prevalence and antibiotic resistance patterns of Salmonella isolates from lactating cows and in-contact humans in dairy farms, Northwest Ethiopia. Journal of environmental and occupational science 4(4): 172.

32. Thrusfield M (2007) Sampling Veterinary Epidemiology. Blackwell Science, Oxford, UK. p. 232.

33. (2008) Clinical and laboratory Standards Institute (CLSI). Performance Standards for Antimicrobial Disk and dilution Susceptibility Tests for Bacteria Isolate from Animals. Clinical Laboratory Standards Institute 28(8): 131-133.

34.Zadernowska A, Chajęcka W (2012) Detection of Salmonella spp. presence in food. In: Salmonella - A Dangerous Food borne Pathogen, In: BSM Mahmoud (Eds.). pp. 393-412.

35. Khaitsa ML, Mantz A, Doetkott D (2004) Prevalence of Escherichia coli 0157: H7 and Salmonella in North Dakota State University (NDSU) Dairy Cattle and antimicrobial susceptibility patterns of the Salmonella isolates. In: Proceedings of the $38^{\text {th }}$ Annual North Dakota Dairy Convention. Mandan, ND. p. 32-35.

36. Alemayehu D, Molla B, Muckel A (2003) Prevalence and antimicrobial resistance pattern of Salmonella isolates from apparently healthy slaughtered cattle in Ethiopia. Tropical Animal Health and Production 35(4): 309-319.

37. Tadesse T, Dabassa A (2012) Prevalence and antimicrobial resistance of Salmonella isolated from raw milk samples collected from Kersa district, Jimma Zone, South west Ethiopia. Journal of Medical Science 12(7): 224228.

38. Tajbakhsh R, Tajbakhsh E, Momeni M, Rahimi E, Sohrabi R (2012) Occurrence and Antibiotic Resistance of Salmonella spp isolated from raw Cow's Milk from Shahahrekord Iran. International Journal of Microbiology 3: 242-245.

39. Amavisit P, Browning GF, Lightfoot D, Church S, Anderson GA, et al. (2001) Rapid PCR detection of Salmonella in horse faecalsamples. Veterinary Microbiology 79(1): 63-74.

40. Abebe A, Rakshit K, Anal K (2013) Genotypic and phenotypic characterization of antimicrobial resistance patterns of Salmonella strains isolated from raw milk in Sebeta, Ethiopia. International Journal of Advanced Life Science 6: 192-199.

41. Fadlalla IM, Hamid ME, Abdel Rahim AG, Ibrahim MI (2012) Antimicrobial susceptibility of Salmonella serotypes isolated from human and animals in Sudan. Journal of Public Health Epidemiology 4(1): 19-23.

42. Sibhat B, Molla ZB, Zerihun A, Muckle A, Cole L, et al. (2009) Salmonella Serovars and Antimicrobial Resistance Profiles in Beef Cattle, Slaughterhouse Personnel and Slaughterhouse Environment in Ethiopia. Zoonoses of Public Health 58(2): 102-109.

43. Stevens A, Kabore Y, Perrier-Gros-Claude JD, Millemann Y, Brisabois A, et al. (2006) Prevalence and antibiotic-resistance of Salmonella isolated from beef sampled from the slaughterhouse and from retailers in Dakar (Senegal). International Journal of Food Microbiology 110(2): 178-186.

44. Al-Bahry SN, Elshafie AE, Al Busaidy S, Al Hinai J, Al-Shidi I (2007) Antibiotic resistant Salmonella spp. from human and non-human sources in Oman. East Mediterranean Health Journal 13(1): 49-55.

45. Khaitsa MR, Kegode RB, Doetkott DK (2007) Occurrence of antimicrobialresistant Salmonella species in raw and ready to eat turkey meat products from retail outlets in the midwestern United States. Food borne Pathogen Disease 4(4): 517-525.

46. Rotimi VO, Jamal W, Pal T, Sonnevend A, Dimitrov TS, et al. (2008) Emergence of multidrug-resistant Salmonella spp. and isolates with reduced susceptibility to ciprofloxacin in Kuwait and United Arab Emirates. Diagnostic Microbiology Infectious Disease 60(1): 71-77.

Cite this article: Fufa A, Getachew N, Takele B T, Dinka A, Berhane W, Hika W, et.al. Occurence and Antimicrobial Susceptibility Profile of Salmonella from Dairy Farms in and Around Meki Town, Oromia, Ethiopia. Biomed J Sci\&Tech Res 6(4)- 2018. BJSTR. MS.ID.001380. DOI: $10.26717 /$ BJSTR.2018.06.001380. 


\section{ISSN: 2574-1241}

DOI: $10.26717 / B J S T R .2018 .06 .001380$

Fufa Abunna. Biomed J Sci \& Tech Res

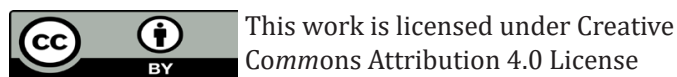

Submission Link: https://biomedres.us/submit-manuscript.php

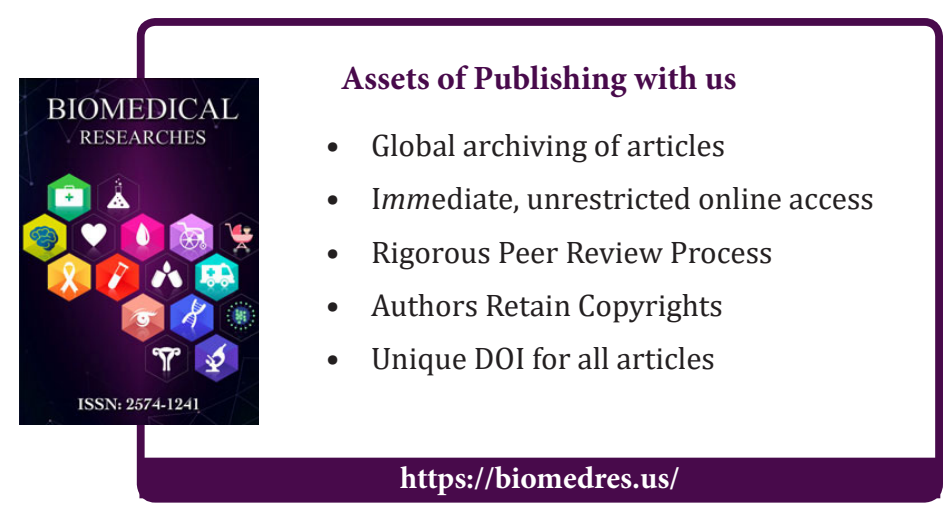

